\title{
Soft Set Approach for Studying the Passenger Behavior in Public Transport System
}

\author{
S.Bharathi \\ Department of Mathematics, Bharathiar University PG Extension Centre, Erode, Tamil Nadu, India
}

\begin{abstract}
The public transit system are essential services to the sustainability and livability of any city. Transit agencies are consistently trying to improve service reliability and attract passengers by applying various strategies. In this paper, we present an approach to mining the temporal behavior of the passengers in a public transportation system, which may help the transport operators to know the demand of the passengers, which may be helpful in redesigning the existing transport system. In our model, the choices between alternatives are based on the factors like cheaper cost, lesser travel time, time convenience, safety, age of the passenger, income of the passenger, work flexibility, working start and end times. The modes of transport under study are Government bus, Private Bus, Mini Bus, taxi and train. Using soft set theoretic approach we arrived at an result about the public's choice in choosing a transport system.
\end{abstract}

Key Words: Passenger behavior, Decision Making Soft set, Choice Matrix

\section{Introduction}

Soft set theory is growing very rapidly since its introduction [4]. The nobel concept of soft set theory plays an important role as a mathematical tool for dealing with uncertainties. For handling real life ambiguous situations we need methodologies which provide some form or other flexible information processing capacity. Soft set theory [2] and [3] is generally used to solve such problems. Zou and Xiao [7]presented data analysis approaches of soft sets under incomplete information. These approaches presented in [7] are preferable for reflecting actual states of incomplete data in soft sets. Cagman et al [5] and [6] introduced a new soft set based decision making method (uni-int decision making method ) [5] which selects a set of optimum elements from the alternatives. Here we present an approach to mining the temporal behavior of the passengers in a public transportation system, which may help the transport operators to know the demand of the passengers, which may be helpful in redesigning the existing transport system. We assume that the travel alternative can be different for different travelers.

\section{Preliminaries}

Definition: [1] Let $\mathrm{U}$ be an initial universe set and $\mathrm{E}$ be a set of parameters. Let $\mathrm{P}(\mathrm{U})$ denotes the power set of $\mathrm{U}$. Let $\mathrm{A} \subseteq \mathrm{E}$. A pair $(\mathrm{F}, \mathrm{E})$ is called a soft set over $\mathrm{U}$, where $\mathrm{F}$ is a mapping given by, $\mathrm{F}: \mathrm{A} \rightarrow \mathrm{P}(\mathrm{U})$.In other words, a soft set over $\mathrm{U}$ is a parameterized family of subsets of the universe $\mathrm{U}$.

Definition: [2] For two soft sets (F, A) and (G,B) over a common universe U, we say that (F,A) is a soft subset of $(\mathrm{G}, \mathrm{B})$ if

(i) $\mathrm{A} \subset \mathrm{B}$, and

(ii) $\forall \quad \varepsilon \in A, \quad F(\varepsilon)$ and $G(\varepsilon)$ are identical approximations.

We write $(\mathrm{F}, \mathrm{A}) \subset(\mathrm{G}, \mathrm{B})$. (F,A) is said to be a soft super set of $(\mathrm{G}, \mathrm{B})$, if $(\mathrm{G}, \mathrm{B})$ is a soft subset of $(\mathrm{F}, \mathrm{A})$.

Definition: [2] If $(\mathrm{F}, \mathrm{A})$ and $(\mathrm{G}, \mathrm{B})$ are two soft sets then " $(\mathrm{F}, \mathrm{A})$ AND $(\mathrm{G}, \mathrm{B})$ ” denoted by $(\mathrm{F}, \mathrm{A}) \wedge(\mathrm{G}, \mathrm{B})$ is defined by

$(\mathrm{F}, \mathrm{A})^{\wedge}(\mathrm{G}, \mathrm{B})=(\mathrm{H}, \mathrm{A} \times \mathrm{B})$,

Where $H(\alpha, \beta)=F(\alpha) \cap G(\alpha), \quad \forall(\alpha, \beta) \in A \times B$.

Definition: [3] Let (F,E) A be a fuzzy soft set over $\mathrm{U}$. Then a subset of $\mathrm{U} \times \mathrm{E}$ is uniquely defined by $R=\{(u, e): e \in A, u \in F(e)\}$ which is called a relation form of $(\mathrm{F}, \mathrm{E})$.Now the characteristic function of $R$ is written by, $\chi_{R}: U \times E \rightarrow[0,1]$ such that $\chi_{R}(u, e)=\mu(u, e)$ where $\mu(u, e)$ is the membership value of the object $\mathrm{u}$ associated with the parameter e. 


\section{Soft Set Approach In Studying Passengers Behaviour}

We assume that the travel alternative can be different for different travelers. In our model, the choices between alternatives are based on four main factors: cost, time, convenience, and safety. The traveler characteristics that we include in our model are: age, income, work flexibility, working start and end times. Modes of transport t1- Government bus, $\mathrm{t} 2$ - Private Bus, $\mathrm{t} 3$ - Mini Bus, $\mathrm{t} 4$-train, $\mathrm{t} 5$-taxi.

Example: Suppose the following.

$\mathrm{U}$ is the set of Modes of transport under consideration.

E the set of Parameters.

$\mathrm{E}=\{$ cost, time, convenience, safety, age, work flexibility, working start and end times $\}$.

In this case, to define a soft set means to point out the cheapest transport, safety transport and so on. The soft Set $(\mathrm{F}, \mathrm{E})$ describes the transport system which Mr.X (say) is going to choose. Let us consider the example in detail for our discussion. Suppose that there are five modes of transport in the universe. Then

$\mathrm{U}=\left\{\mathrm{t}_{1}, \mathrm{t}_{2}, \mathrm{t}_{3}, \mathrm{t}_{4}, \mathrm{t}_{5}\right\}$ and $\mathrm{E}=\left\{\mathrm{e}_{1}, \mathrm{e}_{2}, \mathrm{e}_{3}, \mathrm{e}_{4}, \mathrm{e}_{5}\right\}$ Where

$\mathrm{e}_{1}$ stands for cost(cheaper mode) of transport

$\mathrm{e}_{2}$ stands for time duration (travel time)

$\mathrm{e}_{3}$ stands for convenience

e4 stands for safety

e5 stands for age of the passenger

Suppose that $\mathrm{F}\left(\mathrm{e}_{1}\right)=\left\{\mathrm{t}_{1}, \mathrm{t}_{3}, \mathrm{t}_{4}\right\}$

$\mathrm{F}(\mathrm{e} 2)=\left\{\mathrm{t}_{2}, \mathrm{t}_{3}, \mathrm{t}_{5}\right\}$

$\mathrm{F}(\mathrm{e} 3)=\left\{\mathrm{t}_{2} \mathrm{t}_{4}, \mathrm{t}_{5}\right\}$

$\mathrm{F}(\mathrm{e} 4)=\left\{\mathrm{t}_{1}, \mathrm{t}_{4}, \mathrm{t}_{5}\right\}$

$\mathrm{F}(\mathrm{e} 5)=\left\{\mathrm{t}_{5}\right\}$

Here $F\left(e_{1}\right)$ means the transport cost which is cheaper $=\left\{t_{1}, t_{3}, t_{4}\right\}$ and so on.

The tabular representation is given by

\begin{tabular}{|c|c|c|c|c|c|}
\hline $\mathrm{U}$ & Cost(cheaper) & Travel time & Convenient & Safety & Age \\
\hline t 1 & 1 & 0 & 0 & 1 & 0 \\
\hline $\mathrm{t} 2$ & 0 & 1 & 1 & 0 & 0 \\
\hline t 3 & 1 & 1 & 0 & 0 & 0 \\
\hline $\mathrm{t} 4$ & 1 & 1 & 1 & 1 & 0 \\
\hline t 5 & 0 & 0 & 1 & 1 & 1 \\
\hline
\end{tabular}

Definition: [3] Choice Matrix: It is a square matrix whose rows and columns both indicate parameters. If $\xi$ is a choice matrix, then its element $\xi(\mathrm{i}, \mathrm{j})$ is defined as follows:

$\xi(i, j)=1$ when $i-$ th and $j-$ th parameters are both choice parameters of the decision makers

$\xi(i, j)=$ average of $i, j$ otherwise.

There are different types of choice matrices according to the number of decision makers.

Now, consider the following decision making problem.

\section{Example 2:}

Let $U$ be a set of four modes of transport, say $U=\{t 1, t 2, t 3, t 4, t 5\}$

Let $\mathrm{E}$ be a set of parameters, given by $\mathrm{E}=\{$ cheaper, less travel time, convenient, safe, working start and end times $\}=\{\mathrm{e} 1, \mathrm{e} 2, \mathrm{e} 3, \mathrm{e} 4, \mathrm{e} 5\}$.The following are the weights given for the parameters.

\begin{tabular}{|c|c|c|c|c|c|}
\hline U & Cost(cheaper) & Travel time & Convenient & Safety & Working time \\
\hline Govt Bus & .7 & .5 & .3 & .9 & .6 \\
\hline Private Bus & .8 & .7 & .4 & .7 & .6 \\
\hline Mini & .8 & .7 & .6 & .5 & .5 \\
\hline Train & .9 & .8 & .9 & .8 & .5 \\
\hline Taxi & .4 & .5 & .9 & .6 & .8 \\
\hline
\end{tabular}

Suppose Mr.X and Mr.Y and Mr.Z wants to choose a public transport of their choice.

Let Mr.X choose a transport which is cheap, lesser travel time, convenient and working start and end times. The choice matrix of $\mathrm{Mr} . \mathrm{X}$ is 


$$
\left(\begin{array}{lllll}
1 & 0 & 0 & 0 & 0 \\
0 & 1 & 1 & 0 & 0 \\
1 & 1 & 0 & 0 & 0 \\
1 & 1 & 1 & 0 & 0 \\
0 & 0 & 1 & 0 & 1
\end{array}\right)
$$

If Mr.Y choose a transport which is cheap, convenience and safe and Mr.Z choose a transport system which is convenient and safe The choice matrix of Mr.Y and Mr.Z are

$$
\left(\begin{array}{lllll}
1 & 0 & 0 & 1 & 0 \\
0 & 0 & 1 & 0 & 0 \\
1 & 0 & 0 & 0 & 0 \\
1 & 0 & 1 & 1 & 0 \\
0 & 0 & 1 & 1 & 0
\end{array}\right) \text { and }\left(\begin{array}{lllll}
0 & 0 & 0 & 0 & 0 \\
0 & 0 & 1 & 0 & 0 \\
0 & 0 & 0 & 0 & 0 \\
0 & 0 & 1 & 0 & 0 \\
0 & 0 & 1 & 0 & 1
\end{array}\right) \text { respectively. }
$$

The combined choice matrix of Mr.X, Mr.Y and Mr.Z is

$$
\left[\begin{array}{ccccc}
0.75 & 0 & 0 & .5 & 0 \\
0 & .25 & 1 & 0 & 0 \\
.75 & .25 & 0 & 0 & 0 \\
.75 & .25 & 1 & 1 & 0 \\
0 & 0 & 1 & 1 & .5
\end{array}\right]
$$

When combined with the weight parameters the choice value for the combined matrix is given by $(1.8,0.55$, $2.2,1.85,0.4)$

Here Max value is 2.2. Therefore the first choice is given by the passenger is for convenient mode of transport, that is the transport which is convenient with time. In the same way the next importance is given to the transport which is safe and so on.

\section{Conclusion}

The soft set theory offers a general mathematical tool for dealing with uncertain, fuzzy or vague objects. Using soft set theoretic approach we tried to study the passenger behavior that what kind of transport facility a person is willing to choose. We have started with only five kind of parameters which can be increased in course of time.

\section{References}

[1]. P. K. Maji, R. Biswas and A. R. Roy, An application of soft sets in a decision making problem, Comput Math Appl. 44(2002), 1077- 1083

[2]. $\quad$ P. K. Maji, R. Biswas and A. R. Roy, Soft Set Theory, ComputMath Appl. 45 (2003), 555-562.

[3]. P. K. Maji, R. Biswas and A. R. Roy, Soft set theory, Comput. Math. Appl. 45 (2003) 555-562.

[4]. D. Molodtsov, Soft set theory-First results, Comput. Math. Appl. 37 (1999) 19-31.

[5]. Naim Cagman, Serdar Enginoglu, Soft Matrix Theory and It's Decision Making, Comput Math Appl., 59(2010), 3308-3314.

[6]. Naim Cagman, Serdar Enginoglu, Soft Set Theory and Uni-int Decision Making, Eur J Oper Res. 207(2010), 848-855.

[7]. Y. Zou, Z. Xiao, Data Analysis Approaches of Soft Sets under Incomplete Information, Knowledge-Based Systems, 21(2008),941-945. 